\title{
Possibilidades da etnomusicologia aplicada no campo da saúde coletiva
}

\author{
Possibilities of ethnomusicology applied to the field of public health
}

Aline Veras Morais Brilhante (https://orcid.org/0000-0002-3925-4898) ${ }^{1}$

Elaine Saraiva Feitosa (https://orcid.org/0000-0003-3006-4710) ${ }^{1}$

Epaminondas Carvalho Feitosa (https://orcid.org/0000-0002-3563-9651) ${ }^{2}$

Ana Maria Fontenelle Catrib (https://orcid.org/0000-0002-2088-0733) ${ }^{1}$

${ }^{1}$ Programa de PósGraduação em Saúde Coletiva, Universidade de Fortaleza. Av. Washington Soares 1321, Edson Queiroz. 60811-905 Fortaleza CE

Brasil. alineveras@unifor.br

${ }^{2}$ Programa de Pós-

Graduação em Direito

e Gestão de Conflitos,

Universidade de Fortaleza.

Fortaleza CE Brasil.

\begin{abstract}
This article analyses methodological possibilities of ethnomusicology in the field of public health, starting from an experience that triangulated ethnomusicological theories with discourse analysis (DA). After an introduction to applied ethnomusicology, it is followed by a description of methodological aspects of the experience in question. Subsequently, the conduction of the ethnomusicological step and the triangulation process was described. Results show that the musical systems are situated in power structures, influencing the construction of subjectivities. Applied ethnomusicology emerges, therefore, as a possibility for analyzing the structures on which the music is rooted in. From a research on the relations between forró and the perception of young people's perception about sexual violence, ethnomusicology presented itself as a theoretical possibility for the study of violent social performances and about the effects of music in identity building, besides providing elements for the confrontation of violence inside the cultural system itself. Its triangulation with DA contributes for an ethnographic-discursive research, as possibility of analysis of social practices.
\end{abstract}

Key words Music, Methodology, Public health
Resumo $O$ artigo analisa possibilidades metodológicas da etnomusicologia no campo da saúde coletiva, partindo de uma experiência que triangulou teorias etnomusicológicas com a análise do discurso (AD). Após uma introdução à etnomusicologia aplicada, segue-se a descrição de aspectos metodológicos da experiência em questão. Em sequência, descreveu-se a condução da etapa etnomusicológica e o processo de triangulação. Os resultados mostram que os sistemas musicais se situam em estruturas de poder, influenciando a construção das subjetividades. A etnomusicologia aplicada emerge, portanto, como possibilidade para a análise das estruturas sobre as quais a música se alicerça. A partir de uma pesquisa a respeito das relações entre o forró e a percepção de jovens sobre a violência sexual, a etnomusicologia apresentou-se como possibilidade teórica para o estudo das performances sociais violentas e dos efeitos da música nas construções identitárias, além de fornecer elementos para o enfrentamento da violência dentro do próprio sistema cultural. Sua triangulação com a AD contribui para uma pesquisa etnográfico-discursiva, como possibilidade de análise das práticas sociais.

Palavras-chave Música, Metodologia, Saúde coletiva 


\section{Introdução}

O fenômeno da violência, em suas diferentes manifestações, não é a-histórico ou destituído de subjetividade $^{1}$. Analisar a violência contra a mulher implica compreender como esses processos atravessam as sociedades e seus mecanismos de naturalização e legitimação ${ }^{2}$, incluindo sua relação com discursos e performances culturais ${ }^{3} \mathrm{e}$ as diferentes tecnologias sociais ${ }^{4}$, que atuam no contínuo processo de formação de identidade culturais $^{3}$ e das performatividades de gênero ${ }^{5,6}$. Emerge assim a necessidade de analisar sua relação com a naturalização da violência contra a mulher, partindo da premissa de que a historicidade é basilar à construção dos processos identitários?

A música atua como um artefato", sendo "interpretada performativamente por uma gama de procedimentos hierárquicos e seletivos $[. .$. subservientes a vários poderes e interesses, dos quais os 'sujeitos' e agentes [...] nunca estão suficientemente conscientes"'. Diante de estudos que associam performances musicais a elementos mantenedores da violência de gênero ${ }^{9-13}$, emergiu a pergunta: como a música contribui para a perpetuação e a legitimação da violência contra a mulher?

Esse questionamento orientou a pesquisa "Gênero, sexualidade e forró: um estudo histórico social no contexto nordestino"14, que analisou os discursos de músicas desse gênero musical desde 1940 até a contemporaneidade. A imersão na temática e na teoria musical conduziu a uma ampliação do escopo metodológico nas pesquisas subsequentes, aproximando-as da etnomusicologia.

Entendendo o comportamento violento e as performances miméticas da violência como parte de um sistema coerente carregado de significado cultural, uma corrente da chamada etnomusicologia aplicada busca a compreensão das capacidades performativas da violência e os significados que as performances violentas carregam para as vítimas, perpetradores e testemunhas ${ }^{15}$. Emergiu daí uma pesquisa ancorada nos pressupostos epistemológicos da etnomusicologia aplicada que objetivou compreender as relações entre as performances ritualísticas do forró e a percepção de jovens sobre a violência sexual ${ }^{16}$.

Entendendo que a etnomusicologia apresenta potencialidades importantes para o campo da saúde coletiva, apresentamos um relato de experiencia sobre sua utilização no $7^{\circ}$ Congresso Ibero-Americano em Investigação Qualitativa ${ }^{17}$.
Nesse contexto, o presente artigo analisa as possibilidades metodológicas do uso da etnomusicologia no campo da saúde coletiva, partindo de uma experiência de pesquisa sobre violência contra a mulher realizada em Fortaleza, Ceará, Brasil, que triangulou teorias etnomusicológicas com a análise do discurso.

\section{Metodologia}

Este artigo se baseia no relato de experiência de uma pesquisa que utilizou a etnomusicologia como matriz teórica, triangulando-a com a análise do discurso. Os dados da pesquisa em questão não serão replicados, posto que já estão disponíveis em outra publicação. Eles serão, contudo, referenciados, a fim de situar a discussão sobre as possibilidades da etnomusicologia no campo da saúde coletiva.

Para embasar a discussão, segue a apresentação da matriz teórica, no caso, a etnomusicologia.

\section{Etnomusicologia}

Procedente da escola de Berlim, puramente musical $^{18}$, a etnomusicologia evoluiu para variantes diversas ${ }^{19}$. Sua vertente de orientação antropológica ${ }^{20,21}$ entende a música como expressão do comportamento sociocultural humano. Essa corrente considera que a música não tem um significado em si e que os sujeitos acrescentam ao seu sentido significações conceitualizadas e referenciadas que não existem na linguagem verbal ${ }^{22}$. O entendimento da música como expressão reveladora do ser humano deu um novo ímpeto à investigação etnomusicológica ${ }^{23}$. Nesse contexto, alguns etnomusicólogos foram buscar em Clifford Geertz a teorização necessária para transpor a análise da experiencia musical ${ }^{24}$. Do mesmo modo que para Geertz, os etnógrafos não estudam a experiência em si, mas as estruturas pelas quais as experiências ocorrem ${ }^{25,26}$, de forma que os etnomusicólogos deveriam se aprofundar nas estruturas sobre as quais a música se alicerça e em seu papel na construção contínua e sustentação dessa estrutura. As performances musicais estão situadas e inseridas dentro de estruturas de poder e influência, sendo em si atos políticos. Onde são realizadas, por quem e para quem, bem como os rituais que as atravessam e sustentam revelam muito sobre o status cultural e social em que se inserem $^{27}$.

Os estudos de pesquisadores como Timoti e Rice forneceram importantes elementos para 
a construção da relação teórica entre música e identidade ${ }^{28-31}$. Rice organiza a teorização dessa vertente da etnomusicologia em dois eixos perpendiculares. Um centra-se na comunidade: (1) estudos geograficamente focados em nações, regiões, cidades, vilas ou aldeias; (2) grupos étnicos, raciais e minoritários; (3) a vida musical de instituições, como escolas, prisões e clubes; e (4) a vida social dos gêneros musicais. O segundo eixo inclui os temas próprios da teoria musical: música e política; o ensino e a aprendizagem de música; conceitos sobre música; gênero e música; entre outros ${ }^{28}$. A compreensão do papel da música na construção das identidades aproximou ainda mais a etnomusicologia de outros ramos das ciências sociais, como os estudos culturais e a teoria marxista ${ }^{32}$. Nesse contexto, Rice descreve seis temas que o autor agrupou sob a alcunha de etnomusicologia em tempos de dificuldade: (1) música, guerra e conflito; (2) música, migração forçada e estudos minoritários; (3) música, doença e cura; (4) música em tragédias particulares; (5) música, violência e pobreza; e (6) música, mudanças climáticas e meio ambiente ${ }^{15}$.

A aproximação com abordagens críticas da diferença (teoria feminista, discurso minoritário, etc.) bem estabelecidas em estudos étnicos, feministas, de cultura popular e literários ${ }^{32}$ culmi- $^{-}$ naram em novas possibilidades epistemológicas para a etnomusicologia. O pesquisador brasileiro Samuel Araújo e seus colegas do Laboratório de Etnomusicologia da Universidade Federal do Rio de Janeiro aproximaram suas pesquisas das ideias de Paulo Freire para realizar um estudo sobre a violência no Rio de Janeiro. Eles partiram do entendimento do funk como um território, tanto na perspectiva funcional como simbólica, e de sua relação com os modos de existência (e resistência) dos moradores da comunidade da Maré, um bairro pobre do Rio de Janeiro. Para além da análise dos discursos musicais e de sua contextualização, o estudo de Araújo questionou a importância das etnografias dialógicas das práticas sonoras para refrear a violência do ponto de vista sócio-científico ${ }^{33}$. Sua pesquisa incorpora a perspectiva de pesquisadores que entendem a música como campo de ação para um sujeito ${ }^{34}$, organizado em linguagem ritual e simbolizada pela historicidade e as relações sociais de $\operatorname{poder}^{27}$.

$\mathrm{O}$ encontro da etnomusicologia com os estudos sobre performance social ${ }^{35}$ descortina o cenário para uma etnomusicologia feminista ${ }^{23}$, para a qual a música tem um papel importante na construção das subjetividades e na introjeção dos papéis de gênero ${ }^{36-39}$. Para além do som, a performance musical atua no processo de socialização, tanto expressando como moldando a ordem social e as relações de gênero ${ }^{23}$. Desse modo, estudos dos comportamentos musicais atuam como indicadores de relações de poder baseadas no gênero, subsidiando estratégias sustentáveis de enfrentamento. Eles transpõem o espaço geográfico de sua execução, na medida em que analisam práticas universais de legitimação da violência atreladas em seus princípios de administração dos corpos e gestão calculista da vida.

\section{Resultados}

Os resultados estão organizados em três subtópicos: o primeiro aborda os aspectos metodológicos da experiência em questão, que serão descritos de forma densa, incluindo referência a estudos prévios, os motivos que levaram à utilização da etnomusicologia e à sua triangulação com a análise do discurso. Na segunda e terceira etapas dos resultados serão descritas, respectivamente, a condução de uma pesquisa de cunho etnomusicológico e o processo de triangulação.

\section{Aspectos metodológicos da experiência}

O forró, mais do que um estilo musical, constitui um fenômeno importante na criação da imagem idiossincrática de um Nordeste único e atemporal que, embora nunca tenha existido ${ }^{40-42}$, foi introjetada, inclusive pelos nordestinos ${ }^{43}$, dando a esse gênero musical status de símbolo cultural nordestino. Nesse contexto, o forró e sua relação com os papéis sociais de gênero se tornaram nosso objeto de estudo.

A análise do discurso das músicas de forró, realizada preliminarmente, havia fornecido informações importantes sobre as formações discursivas e ideológicas que permeiam as letras. Emergiu dessa pesquisa, contudo, a necessidade de analisar a relação entre o forró, os corpos e as subjetividades em seu contexto real de interação. Desse modo, durante oito meses, entre março e novembro de 2014, pesquisadoras e equipe técnica experienciaram uma imersão profunda no cotidiano do bairro de Fortaleza com piores índices de violência contra a mulher ${ }^{44}$. $\mathrm{O}$ bairro em questão agrega uma série de vulnerabilidades: com Índice de Desenvolvimento Humano (IDH) de $0,403^{44}$, está localizado na regional mais populosa de Fortaleza (com 585.347 habitantes), que também é a mais pobre, com rendimento familiar médio de 3,07 salários mínimos, e a segunda 
em índice de analfabetismo (17,83\%). Não é à toa que o bairro pertence à Área Integrada de Segurança (AIS) 2, território com o maior registro de homicídios em Fortaleza ${ }^{45}$. Considerando que a cidade está localizada no Nordeste, região brasileira com os maiores números de feminicídio ${ }^{46}$, o bairro em questão se apresentou como um cenário apropriado para a pesquisa proposta.

A partir daí, foram realizadas observações etnomusicológicas no cotidiano do bairro, com foco na relação entre as pessoas e as músicas que ressoam pelo bairro. Além disso, realizou-se observações etnográficas nos bailes de forró, observando estrutura física, som, performances sociais, dinâmica das festas e as relações entre homens e mulheres em situações reais. As descrições densas e detalhadas no diário de campo forneceram um panorama amplo da relação entre a música e os papéis sociais de gênero. Esse conhecimento foi crucial para o planejado na etapa subsequente.

No segundo momento da pesquisa, foram realizados, em 2015, dois grupos focais com 14 rapazes entre 14 e 18 anos matriculados nas duas escolas estaduais de ensino fundamental e médio do bairro. Após explicações preliminares, foram reproduzidas três músicas de forró escolhidas previamente. Após cada música, iniciava-se o debate acerca do significado de seus conteúdos. As discussões foram gravadas e transcritas na íntegra e analisadas segundo os princípios da análise do discurso ${ }^{47}$. Os achados dessa pesquisa encontram-se publicados ${ }^{16}$ e não pretendemos aqui repeti-los. $\mathrm{O}$ artigo que ora se apresenta se concentra nos aspectos metodológicos que guiaram o estudo, buscando discorrer sobre as possibilidades da etnomusicologia em uma pesquisa no campo da saúde coletiva.

\section{A imersão no mundo musical cenário - a violência vivida nos acordes e batidas}

A aproximação com a realidade musical do bairro apresentou inúmeros desafios. O primeiro decorre da própria concepção de pesquisa etnomusicológica. Esta é geralmente entendida como o estudo de uma cultura musical alheia à experiência do pesquisador, a fim de identificar os códigos internos às culturas observadas. Apesar da participação de uma antropóloga experiente na pesquisa, a imersão na cultura musical exigiu das pesquisadoras a observação e registro dos aspectos musicais, além do adensamento teórico nos campos da musicologia. Outro desafio foi o acesso ao campo, que demandou a autorização por parte dos grupos de facções que comandam a região.
Dessa forma, as autoras vivenciaram uma imersão no cenário. A observação etnomusicológica de cunho etnográfico demanda uma aproximação humilde diante dos códigos culturais que orquestravam sons, performances e movimentos locais. Esse processo requer múltiplos instrumentos de coleta de dados, incluindo observação não participante e participante, descrições minuciosas no diário de campo e registros audiovisuais do cotidiano do bairro. Para além da estrutura e dos hábitos e interações socioculturais que nela se organizam, as pesquisadoras estiveram atentas à cultura musical do bairro e à sua relação com as performances individuais e de grupos. Desse modo, buscou-se uma densa imersão sônica. Foram observados e registrados os diversos estilos musicais que vibravam no cotidiano diário do bairro, além das performances individuais e sociais construídas em torno dessas músicas. Sons de rádios domiciliares que transpunham as paredes das casas, carros de som, a música nos estabelecimentos comerciais, os toques de celulares toda música era observada e registrada. Em meio ao funk e à música sertaneja, o forró se destacou. As conversas com os moradores envolviam perguntas sobre o cotidiano do bairro, mas também acerca da influência da música na identidade cultural dos moradores. Sendo a violência contra a mulher o objeto da pesquisa, as relações entre os gêneros - incluindo as performances sociais e a influência da música sobre elas - foram centrais às observações.

À observação da vida cotidiana, somou-se a imersão na noite do bairro e sua relação com o forró. Para tanto, foram realizadas imersões nas seis casas de forró que animam sua paisagem. As observações foram realizadas por seis meses em noites diversas durante os fins de semana. A observação começou pela estrutura física, comum a todas as casas. Os muros que cercam os terrenos, os buracos na parede que funcionam como bilheterias, as entradas e saídas estreitas, organização do palco, enfim, toda a estrutura foi rigorosamente descrita. Nesse cenário, organizavam-se performances reproduzidas de forma ritualística, com sequências temporais, hierarquias, regras, interditos e obrigações ${ }^{48}$, tanto no palco como no salão de dança. A observação de vestuário, música, dança, movimentos corporais, modos de abordagem e mudanças desses aspectos com a sequência temporal permitiu entender a organização ritualística do forró para aquelas pessoas e sua relação com a introjeção de papéis sociais de gênero estruturados hierarquicamente. 


\section{Triangulando a etnomusicologia e a análise do discurso}

Após a imersão etnomusicológica, realizaram-se os grupos focais com os adolescentes. $\mathrm{O}$ conhecimento adquirido pela primeira etapa da pesquisa e pelo estudo histórico-social das músicas de forró foi crucial para a organização e condução da etapa subsequente. Doze músicas haviam sido eleitas em estudo prévio ${ }^{14}$, baseando-se na presença de elementos associados à violência sexual. Durante a imersão no cotidiano do bairro, a partir da observação dos sons cotidianos e das festas, bem como da reprodução midiática nos meios de comunicação mais presentes no bairro, esse grupo foi reduzido para três músicas ${ }^{16}$.

Para além do planejamento da coleta, a triangulação com a etnomusicologia potencializou o alcance da análise dos dados. O ritual do forró - como a maioria dos sistemas musicais - envolve música, dança e comportamento. A análise do discurso requer contextualização. Nesse contexto, em uma pesquisa que se propõe a analisar os discursos de jovens sobre músicas de forró que remetem à violência sexual, a observação etnomusicológica os situa de forma ímpar, permitindo a compreensão do funcionamento das práticas sociais relacionadas à música e ao seu papel na construção das identidades.

\section{Discussão}

Diante da diversidade epistemológica que compõe a etnomusicologia, sua vertente aplicada busca uma forma de teorizar sobre o campo e atuar sobre ele ${ }^{49}$. Os comportamentos miméticos da violência são parte de um sistema carregado de significado cultural. Não à toa os resultados da pesquisa aqui referenciada evidenciaram concordância entre o forró e outros artefatos culturais. A compreensão teórica dos efeitos da performance musical em identidades e subjetividades fornecem, portanto, elementos para que o enfrentamento à violência e a outros problemas de saúde pública ocorram dentro e por meio desse mesmo sistema cultural ${ }^{15,50}$. Vale ressaltar, contudo, que a etnomusicologia aplicada transpõe a teorização da música como fato sonoro evocativo de outros elementos do contexto, demandando a análise dos processos pelos quais o som é apreendido ${ }^{24}$.

Os diversos sistemas musicais costumam ter em comum uma complexidade semântica. $\mathrm{O}$ termo Forró, por exemplo, não se restringe à música, sendo utilizado para denominar também a dança, as festas e os espaços onde estas ocorrem. Esses elementos, em conjunto, culminam em performances ritualísticas que atuam como intensificadores das práticas sociais internalizadas em uma interação transgeracional contínua ${ }^{27}$. Assim como são social e culturalmente situados, os sistemas musicais se tornam também eticamente saturados. Nossos valores mais profundos estão implícitos na estruturação ritual dos sistemas musicais mais complexos ${ }^{27}$. Os sistemas musicais, contudo, não funcionam apenas como repositórios de valores culturais. Atuam na construção das subjetividades e na introjeção dos papéis de gênero ${ }^{31,36-39}$. Estudos etnomusicológicos podem, portanto, apontar indicadores de relações de poder baseadas no gênero, subsidiando estratégias sustentáveis de enfrentamento dentro da própria cultura.

Em áreas de conflito é frequente que os grupos rivais utilizem sistemas culturais para calar, antagonizar, exacerbar diferenças, aterrorizar e até mesmo torturar os inimigos ${ }^{15}$. Por outro lado, práticas musicais também são utilizadas como estratégia de transformação e resistência. Um estudo realizado em 2013 no Sri Lanka, por exemplo, aborda o surgimento de músicas contra ou fora das línguas comunais promovidas pelos dois exércitos que travavam uma guerra civil no país. Essa pesquisa explorou tais músicas como possibilidades de resistência e de construção de novas culturas nacionais que favoreçam a liberdade psicológica e cultural da população ${ }^{51}$. Estudo realizado em uma comunidade pobre e marcada pela violência no Rio de Janeiro, Brasil, aproximou a etnomusicologia das ideias de Paulo Freire, a fim de construir conexões sociais horizontais entre os pesquisadores e a população ${ }^{33}$. Inspirados no estudo de Araújo, os jovens participantes da pesquisa foram convidados a compor um projeto de extensão que visava não apenas debater as músicas, mas desconstruí-las e reconstruí-las, com o objetivo de enfrentar a violência cultural.

Essas recentes possibilidades epistemológicas da etnomusicologia constroem um cenário favorável à sua triangulação com outras teorias de base crítica, como é o caso da maioria das abordagens que se denominam de análise do discurso. Segundo Orlandi, os sentidos não são produzidos pelo sujeito, mas sim em outro lugar, anterior e externo a ele, posto que "a linguagem está materializada na ideologia e a ideologia se manifesta na língua" ${ }^{2}$. A compreensão do funcionamento das práticas sociais e de suas relações com o discurso demanda, portanto, uma contextualização, sendo beneficiada por uma experiência imersiva 
no campo. Nesse sentido, Magalhães, Martins e Resende propõem uma pesquisa etnográficodiscursiva, segundo a qual a análise de discurso se aproxima de estudos de cunho etnográfico, em uma relação de complementaridade, a fim de analisar as práticas sociais ${ }^{53}$. Neste caso, uma pesquisa que analisa os discursos de sistemas musicais e sua relação com problemas de saúde pública (no caso em questão, a violência sexual) encontra na triangulação com a etnomusicologia uma prática profícua.

\section{Conclusão}

A etnomusicologia, em suas vertentes aplicadas e com viés crítico, apresenta-se como possibilidade epistemológica dentro do campo da saúde coletiva. A pesquisa aqui relatada possibilitou a teorização do papel do forró, como sistema musical complexo, na internalização de relações violentas entre os gêneros. Para além disso, construiu o cenário para o desenvolvimento de práticas transformadoras de enfrentamento da violência, situadas dentro do próprio sistema cultural do forró. A etnomusicologia surge, neste contexto, como uma possibilidade de compreensão e transformação do mundo social no qual as relações assimétricas de gênero são performadas.

\section{Colaboradores}

O manuscrito foi escrito por ES Feitosa. AVM Brilhante contribuiu na pesquisa, redigiu a metodologia e elaborou redação final. AMF Catrib realizou a revisão intelectual do manuscrito. EC Feitosa atuou na revisão intelectual e na formatação final. 


\section{Referências}

1. Wieviorka M. La violence: voix et regards. Paris: Éditions Balland; 2004.

2. Minayo MCDS. Violência: um problema para a saúde dos brasileiro. In: Souza ER, Minayo MCDS. Impacto da violência na saúde dos brasileiros. Brasília: Ministério da Saúde; 2005. p. 9-41.

3. Scott JW. Gênero: uma categoria útil de análise histórica. Educ Real 1995; 20(2):71-99.

4. Lauretis T. A tecnologia do gênero. In: Hollanda HB, organizadora. Tendências e impasses - o feminismo como crítica da cultura; 1994 . p. 206-241.

5. Butler J. Problemas de gênero: feminismo e subversão da identidade. Rio de Janeiro: Editora Record; 2003.

6. Butler J. Bodies that matter: on the discursive limits of sex. Londres: Routledge; 2011.

7. Hall S. Representation: cultural representations and signifying practices (v. 2). London/Thousand Oaks/New Delhi: Sage/Open University; 1997.

8. Derrida J. The deconstruction of actuality: an interview with Jacques Derrida. Radic Philos 1994; 68:2841.

9. Cohen S, Scene MM. Rock music and the production of gender. In: Whiteley S. Sexing the groove: popular music and gender. Routledge: New York; 1997. p.17-36.

10. Faria CN. Puxando a sanfona e rasgando o nordeste: relações de gênero na música popular nordestina (1950-1990). Mneme - Revista de Humanidades 2002; $3(5)$.

11. Maia AF, Antunes DC. Música, indústria cultural e limitação da consciência. Rev Subjetividades 2016; 8(4):1143-1176.

12. Honório MD. Cachaceiro e raparigueiro, desmantelado e largadão! - uma contribuição aos estudos sobre homens e masculinidades na região nordeste do Brasil [tese]. São Paulo: Universidade Estadual Paulista; 2012.

13. Trotta F. Música popular, moral e sexualidade: reflexões sobre o forró contemporâneo. Rev Contracampo 2009; 20:132-146.

14. AVM. Gênero, sexualidade e forró: um estudo histórico social no contexto nordestino [tese]. Fortazela: Universidade de Fortaleza; 2015.

15. Rice T. Ethnomusicology in times of trouble. Yearb Tradit Music 2014; 46:191-209.

16. Brilhante AVM, Nations MK, Catrib AMF. "Taca cachaça que ela libera": violência de gênero nas letras e festas de forró no Nordeste do Brasil. Cad Saude Publica 2018; 34(3):e00009317.

17. Brilhante AVM, Catrib AMF, Feitosa ES, Feitosa EC. A etnomusicologia aplicada à pesquisas em saúde coletiva. CIAIQ 2018; 2:849-858.

18. Rhodes W. Toward a definition of ethnomusicology. Am Anthropol 1956; 58(3):457-463.

19. Krader B. Ethnomusicology. In: New Grove dictionairy of music and musicians. London, Washington, DC: Macmillan Publishers Limited; 1980. p.275-282.

20. Merriam AP. The anthropology of music. Evanston, Illinois: Northwestern University Press; 1964.

21. Blacking J. How musical is man? Seattle: University of Washington Press; 2000.

22. Imberty M. Perspectives nouvelles de la sémantique musicale expérimentale. Musique en jeu 1975; 17:9091.
23. Koskoff E. Ethnomusicology: writings on music and gender. Chicago: University of Illinois Press; 2014.

24. Downey G. Listening to capoeira: phenomenology, embodiment, and the materiality of music. Ethnomusicology 2002; 46(3):487-509.

25. Geertz C. Art as a cultural system. MLN 1976; 91(6):1473-1499.

26. Geertz C. Local knowledge: further essays in interpretive anthropology. Basic books; 2008.

27. Trehub SE, Becker J, Morley I. Cross-cultural perspectives on music and musicality. Philos Trans $R$ Soc B 2015; 370:20140096.

28. Rice T. Disciplining ethnomusicology: a call for a new approach. Ethnomusicology 2010; 54(2):318-325.

29. Timoti R. Reflections on music and identity in ethnomusicology. Musicology 2007; 7:17-38.

30. Rice T. President's soundbyte: what are we thinking? SEM Newsl 2005; 39(4):1-3.

31. Sugarman JC. The nightingale and the partridge: singing and gender among Prespa Albanians. Ethnomusicology 1989; 33(2):191-215.

32. Wong D. Ethnomusicology and difference. Ethnomusicology 2006; 50(2):259-279.

33. Araújo S. Conflict and violence as theoretical tools in present-day ethnomusicology: notes on a dialogic ethnography of sound practices in Rio de Janeiro. Ethnomusicology 2006; 50(2):287-313.

34. Sugarman JC. Building and teaching theory in ethnomusicology: A response to Rice. Ethnomusicology 2010; 54(2):341-344.

35. Cusick SG. Feminist theory, music theory, and the mind/body problem. Perspect New Music 1994; 32(1):8-28.

36. Järviluoma H, Moisala P, Vilkko A. Gender and qualitative methods. London: Sage; 2003.

37. Daukeyeva S. Gender in Kazakh dombyra performance. Ethnomusicology Forum 2016; 25(3):283-305.

38. Murchison G. Mary Lou Williams's girl stars and the politics of negotiation: jazz, gender, and Jim Crow. In: Sullivan JM, editor. Women's bands in America - performing music and Gender. London: Rowman \& Littlefield; 2016. p. 169-228.

39. Mello MIC. Os cantos femininos Wauja no Alto Xingu. In: Matos CN, Travassos E, Medeiros FT. Palavra cantada - ensaios sobre poesia, música e voz. Rio Janeiro: 7 Letras; 2008. p. 238-248.

40. Fernandes A. Forró: música e dança de raiz. In: $V$ Congresso Latino-Americano da Associação Internacional para o Estudo da Música Popular. Rio de Janeiro: Anais; 2004.

41. Silva EL. Forró no asfalto: mercado e identidade sociocultural. São Paulo: Annablume/Fapesp; 2003.

42. Santos JF. Luiz Gonzaga, a música como expressão do Nordeste. São Paulo: Ibrasa; 2004.

43. Albuquerque Júnior DM. A invenção do Nordeste e outras artes. São Paulo: Cortez Editora; 2009.

44. Observem. Filtro de pesquisa sobre a violência contra a mulher em Fortaleza [Internet]. 2016 [acessado 2016 out 20]. Disponível em: https://woese.com/profile/observem 
45. Ceará. Secretaria de Segurança Pública e Defesa Social. Indicadores criminais 2017 [documento na Internet]. 2017. [acessado 2019 ago 15]. Disponível em: https://www.sspds.ce.gov.br/estatisticas-2-2/

46. Moura R. Mapa da criminalidade e da violência em Fortaleza - Perfil da SERV; 2011. [acessado 2021 jun 21]. Disponível em: https://www.yumpu.com/pt/ document/read/27455959/mapa-da-criminalidade-eda-violencia-em-fortaleza-uece

47. Orlandi EP. Análise do discurso: princípios e procedimentos. Campinas: Pontes; 2009.

48. Goffman E. A ritualização da feminilidade. Os momentos e os seus homens. Lisboa: Relógio D’água; 1999. p. 154-189.

49. Harrison K. Epistemologies of applied ethnomusicology. Ethnomusicology 2012; 56(3):505-529.

50. Van Buren KJ. Applied ethnomusicology and HIV and AIDS: responsibility, ability, and action. Ethnomusico$\log y$ 2010; 54(2):202-223.

51. Sykes J. Culture as freedom: musical "liberation" in Batticaloa, Sri Lanka. Ethnomusicology 2013; 57(3): 485-517.

52. Orlandi EP. As formas do silêncio: no movimento dos sentidos. Campinas: Editora Unicamp; 1997.

53. Magalhães I, Martins AR, Resende VM. Análise de discurso crítica: um método de pesquisa qualitativa. Brasília: Editora UnB; 2017.

Artigo apresentado em 02/06/2019

Aprovado em 18/11/2019

Versão final apresentada em 20/11/2019

Editores-chefes: Romeu Gomes, Antônio Augusto Moura da Silva 